\title{
"MONSTRUOSOS» PATRIARCADOS. LOS PATRIARCADOS DE LISBOA E INDIAS FRENTE A LA REVOLUCIÓN LIBERAL EN PORTUGAL Y ESPAÑA*
}

\author{
POR \\ DAVID MARTíNEZ VILCHES ${ }^{1}$ \\ Universidad Complutense de Madrid
}

\begin{abstract}
RESUMEN
Este artículo analiza los proyectos y las realidades de cambio que protagonizaron el Patriarcado de Lisboa y el Patriarcado de Indias en Portugal y España, respectivamente, durante la Revolución liberal. Esta óptica comparativa nos lleva a considerar, además del complicado acomodo de una institución propia del Antiguo Régimen al nuevo sistema impuesto por el liberalismo, la dificultad de establecer límites nítidos entre las esferas de actuación del Estado liberal y la Iglesia en un momento caracterizado por la confrontación entre ambas instancias. Pero también, paradójicamente, cómo estas instituciones que tantos recelos suscitaban podían acomodarse, no sin contradicciones, al nuevo contexto, en el que en ambos países ibéricos se planteaba el paso de Monarquía a nación conservando la religión como elemento definitorio para asegurar que las antiguas lealtades revertían en el nuevo sistema liberal.
\end{abstract}

PALABRAS CLAVE: Patriarcado de Indias; Patriarcado de Lisboa; nación católica; revolución liberal.

\section{"MONSTROUS» PATRIARCHATES. THE PATRIARCHATES OF LISBON AND INDIES FACING THE LIBERAL REVOLUTION IN PORTUGAL AND SPAIN}

\begin{abstract}
This article analyses the projects and realities of change experienced by the Patriarchate of Lisbon and the Patriarchate of the Indies in Portugal and Spain, respectively, during the Liberal Revolution. This comparative perspective leads us to consider, in addition to the complicated accommodation of an institution of the Ancien Regime to the new system imposed by liberalism, the difficulty of establishing clear boundaries between the spheres of action of the liberal State and the Church at a time characterised by the confrontation between both instances. Nevertheless, paradoxically, it also reveals how these institutions which generated suspicion among the liberals could be accommodated, not without contradictions, to the new context, as in both Iberian countries the passage from Monarchy to nation was developed, keeping religion as a defining element to ensure that the old loyalties reversed in the new liberal system.
\end{abstract}

KEY WORDS: Patriarchate of Indies; Patriarchate of Lisbon; catholic nation; liberal revolution.

Cómo CITAR ESTE ARTículo / CITATION: Martínez Vilches, David. 2020. «"Monstruosos” patriarcados. Los Patriarcados de Lisboa e Indias frente a la revolución liberal en Portugal y España». Hispania Sacra LXXII, 146: 515-523. https://doi.org/10.3989/hs.2020.038

\author{
Recibido/Received 10-06-2019
}

Aceptado/Accepted 17-01-2020

\footnotetext{
* Este trabajo se integra dentro del proyecto de investigación "Cultura del honor, política y esfera pública en la España liberal (1833-1890)» financiado por el Ministerio de Ciencia, Innovación y Universidades (PGC2018-093698-B-100) y en el Programa de Formación del Profesorado del Universitario (FPU 17/00545). El autor agradece a la Profesora Raquel Sánchez las sugerencias realizadas sobre el manuscrito original.

1 damart06@ucm.es / ORCID iD: https://orcid.org/0000-0002-5157-2880
} 


\section{INTRODUCCIÓN}

Tanto en España como en Portugal, con motivo de la expansión ultramarina, se instauraron en el Antiguo Régimen sendos Patriarcados para asegurar la vinculación eclesiástica de los nuevos territorios a las metrópolis de origen: el Patriarcado de las Indias Occidentales en Castilla y el Patriarcado de Lisboa en Portugal. En ambos casos, esta institución eclesiástica se convirtió en un asunto que no era ni estrictamente estatal, ni totalmente religioso, sino que se encontraba a medio camino entre la Corona, el Estado y la Iglesia. Su vinculación con la Corona estribaba en que en ambos países ibéricos el Patriarcado estaba íntimamente relacionado con la Capilla Real, esto es, la dependencia palatina encargada del culto solemne en Palacio y de la representación religiosa de la Monarquía, siendo el Patriarca la cabeza visible de esa institución en su calidad de Pro-Capellán en España y de Capellán Mayor (capelão-mor) en Portugal. Respecto al Estado, y en tanto que el Rey era el jefe supremo de los Ejércitos, era razonable que su capellán fuese, al mismo tiempo, el responsable de la atención espiritual de los soldados, ejerciendo la jurisdicción castrense. Y, finalmente, en lo que concierne a la Iglesia, los Patriarcas eran elegidos por los soberanos en virtud de su patronazgo sobre la Iglesia en sus respectivos territorios, pero como dignidades eclesiásticas debían ser confirmados por el Papa en consistorio. ${ }^{2}$

Con la llegada del liberalismo a la Península Ibérica, fue difícil armonizar la institución del Patriarcado con el nuevo sistema liberal, deseoso de reformar la Iglesia tanto en Portugal como en España. Y, a los ojos de los liberales, aparecía como una institución demasiado derrochadora, privilegiada en exceso y muy poco dispuesta a encajar en el nuevo orden de cosas. No en vano, desde las filas liberales de los dos países ibéricos se atacaba a la institución del Patriarcado calificándolo con el adjetivo de "monstruoso». Así, en la misma sesión de las Cortes portuguesas en 1823 el jurista Manuel Borges Carneiro se refería a «Este monstruoso corpo chamado patriarcal, que certamente não caberia em Allemanha, e muito menos em Portugal»; mientras su colega Agostinho José Freire afirmaba que «He realmente difficultoso achar um corpo mais impolitico e mais monstruoso, do que a patriarcal». ${ }^{3}$ Al otro lado de la frontera, algunas décadas después, Ángel Fernández de los Ríos, en el contexto de euforia por el triunfo de la Revolución de 1868, exclamaba: «iQuién se acordará de exigir la abolición de los enclavados exentos de la jurisdicción civil, de los distritos privilegiados, de la monstruosa patriarcal!». ${ }^{4}$

El uso de un mismo adjetivo para calificar estas instituciones en ambos países ibéricos en el momento de tránsito hacia el sistema liberal nos pone sobre la pista de posibles coincidencias a uno y otro lado de la frontera. Por ello, estas páginas examinan desde una óptica comparativa los proyectos y las realidades de cambio que protagonizarían el Patriarcado de Lisboa y el Patriarcado de Indias en Portugal

\footnotetext{
2 Abreviaturas utiliazdas: AGP = Archivo General de Palacio; ANTT, FCC = Arquivo Nacional Torre do Tombo, fondo Família Costa Cabral; BNE = Biblioteca Nacional de España.

3 Para esta cita y la anterior, Diario das Cortes da Nação Portugueza. Segunda Legislatura, 30 de enero de 1823.

4 Fernández de los Ríos 1868, 8.
}

y España durante la Revolución liberal. Ello nos lleva a considerar, además del complicado acomodo de una institución propia del Antiguo Régimen a la nueva realidad impuesta por el liberalismo, la dificultad de establecer límites nítidos entre las esferas de actuación del Estado liberal y la Iglesia en un momento caracterizado por la confrontación, más o menos abierta, entre ambas instancias. Pero también, paradójicamente, cómo estas instituciones que tantos recelos suscitaban podían acomodarse, no sin contradicciones, al nuevo contexto en un momento en el que se planteaba el paso de Monarquía a nación conservando la religión como elemento definitorio para asegurar que las antiguas lealtades revertían en el nuevo sistema. ${ }^{5}$

\section{La RECONVERSión del PATRIARCADO de LISBOA}

En Portugal, al igual que en Castilla, la institución del Patriarcado estuvo relacionada con el ajuste de la administración eclesiástica a la expansión ultramarina, si bien su establecimiento fue más tardío que en el reino vecino. Lisboa era archidiócesis desde 1394, y de ella eran sufragáneas los distintos obispados que se fueron creando en Asia, África y América. Sin embargo, con la complejización de la administración eclesiástica en la segunda mitad del siglo XVII, la capital de la Monarquía necesitaría un estatuto canónico superior que mantuviese su jerarquía sobre las demás diócesis. Ello se hizo especialmente evidente tras la elevación de Bahía a archidiócesis y sede metropolitana de Brasil en 1676. Así, el 7 de noviembre de 1716 Clemente XI elevó la Capilla Real a Iglesia Patriarcal bajo la jurisdicción de un Patriarca que también ostentaría el cargo de Capellán Mayor del Rey y responsable de la jurisdicción eclesiástica castrense. Por el momento se mantenía la jurisdicción territorial del antiguo arzobispo de Lisboa, que quedaría finalmente incorporada a la Iglesia Patriarcal el 13 de diciembre de 1740. Con esta institución religiosa singular el Rey de Portugal se aseguraba la unificación y centralización de la Iglesia lusitana y también de la propia Monarquía, mientras que el Papa reafirmaba el carácter universal del catolicismo. Pero en seguida comenzaron a surgir voces que veían esta corporación eclesiástica como un dispendio extravagante y anacrónico. Como ha sugerido un estudioso de esta institución: "o Patriarcado de Lisboa era uma instituição típica do Antigo Regime, que nasce quando este se prepara para morrer». ${ }^{6}$

En el Trienio Vintista ya se planteó el problema de la Iglesia Patriarcal como un cuerpo eclesiástico sobredimensionado y, además, susceptible de ser utilizado políticamente en contra del sistema liberal por su ascendiente sobre los eclesiásticos portugueses. Y ello especialmente porque el propio Patriarca, Carlos da Cunha, apenas disimulaba su contrariedad frente a los nuevos derroteros por los que iba el país. La confrontación abierta llegó en marzo de

5 Se trata de un objeto de estudio ampliamente abordado por la historiografía española: Portillo Valdés 2006, 2007 y 2012; Alonso 2014; Millán y Romeo 2015. Respecto a la historiografía portuguesa, aunque referido a un período posterior, es imprescindible el estudio de Pinto 2017.

6 Matos 2016, 94. Esta pequeña obra propone una aproximación del Patriarcado de Lisboa en clave nacional, pero no aborda exhaustivamente la historia de la institución. 
1821, cuando el Patriarca se negó a jurar los artículos 10. y 17. de las Bases Constitucionales, ley fundamental basada en la Constitución de Cádiz de 1812 y que se mantendría en vigor hasta la redacción de una nueva Constitución. En concreto, esos artículos hacían referencia a la censura eclesiástica en las obras de dogma y moral, que quedaba en manos de los obispos auxiliados por el Estado, y la afirmación del catolicismo romano como religión de la nación. El patriarca Cunha entendía que, en lo primero, el gobierno se inmiscuía en asuntos de exclusiva competencia eclesiástica mientras que, respecto a lo segundo, no dejaba claro que el catolicismo fuese la única religión del país. Así, tras recluirse en el convento de Buçaco y delegar su jurisdicción en el Colegio Patriarcal, pasó a Bayona, desde donde dirigió una carta pastoral exhortando a los fieles a que permaneciesen constantes en la fe frente a los que consideraba «impios», «novos e falsos filósofos» y "verdadeiros precursores do Antechristo». ${ }^{7}$

Por su parte, las Cortes ordenaron el 15 de noviembre de 1821 que el Gobierno impetrase cuanto antes una bula que extinguiese la Iglesia Patriarcal y restableciese la antigua Iglesia Metropolitana de Lisboa, así como la Capilla Real. Pero lo cierto es que cualquier intento de diálogo con Roma era infructuoso, por lo que el 19 de agosto de 1822 las Cortes acabaron decretando la extinción de la Iglesia Patriarcal y el restablecimiento de la antigua Metrópoli Arzobispal, si bien insistían en la necesidad de que una bula de la Santa Sede sancionase este cambio. Junto a la motivación de tipo económico, el decreto mencionaba que el Patriarcado era incompatible con los deberes de la justicia, y fundamentaba su resolución basándose en que Roma había concedido a los reyes portugueses la facultad de ingresar al Estado los remanentes del Patriarcado, lo que en ese momento, y dadas las urgencias que había de atender el Estado que ahora se iba a encargar del sustento del culto católico, bastaba para acabar con la Patriarcal. El restablecimiento de la Metrópoli Arzobispal de Lisboa se haría en los términos de la bula de 1394 de Bonifacio IV, restaurándola en su composición anterior al establecimiento de la Iglesia Patriarcal, al tiempo que el Estado aseguraría el mantenimiento de aquellos ministros que sobrasen. A su vez, dos días después, las Cortes decretaban que el Tesoro Público consignaría una cantidad de dieciséis millones de reales para que el Rey formase su propia capilla, mientras que los rendimientos que hasta entonces habían estado destinados a la Capilla Real revertirían en los bienes de la nación. ${ }^{8}$

No obstante, la primera experiencia liberal en Portugal tendría escaso recorrido debido a la actuación de las fuerzas absolutistas, unidas en torno al príncipe Miguel, que propiciarían una involución política a fines de la primavera de 1823 que pondría fin al sistema constitucional. En agosto volvería Cunha, convertido en referente de la contrarrevolución, y con motivo de su regreso escribiría otra carta pastoral celebrando el final de "o anti-fisolofico systema de Governo, que com apparencia de reforma e melhoramento

\footnotetext{
7 Carta pastoral de Cunha, fechada el 8 de septiembre de 1821, en Aniceto 2017, 362. Sobre el patriarca Cunha, véase la síntesis biográfica que ofrece Ponces 2009.

8 Estas disposiciones en: Collecção dos decretos 1822, 279; Diario das Cortes Geraes e Extraordinarias da Nação Portugueza, n. 15, 19 de agosto de 1822; y Collecção das cartas de lei 1822, 409-410.
}

se pertendia estabelecer» para desgracia de la religión y la patria. ${ }^{9}$ El 14 de diciembre moría Cunha y pocos días después era elegido el agustino Patrício da Silva, que ya se había revelado como un apologeta contra las doctrinas modernas desde la sede de Évora. También fue nombrado consejero de Estado para auxiliar a la infanta Isabel María durante la enfermedad de Juan VI. Sin embargo, tras la muerte de este, y después de un titubeo inicial en apoyo a Pedro IV, decantó su lealtad por Miguel I, a quien otorgaba la legitimidad de ostentar el trono lusitano, toda vez que su hermano mayor era Emperador de una nación extranjera, Brasil, y, por tanto, también extranjero. ${ }^{10}$ Contribuía con ello a alimentar el discurso contrarrevolucionario miguelista, que compartía sus principios generales con los demás movimientos absolutistas y legitimistas europeos. ${ }^{11}$ No obstante, tras la victoria de las armas liberales, Silva no tendría otro remedio que reconocer a María II. ${ }^{12}$

El 4 de febrero de 1834 se decretó nuevamente la extinción de la Iglesia Patriarcal. En el preámbulo del decreto, el ministro José da Silva Carvalho afirmaba que hacía tiempo que esta institución sufría de falta de medios, y en aquel momento las dificultades eran «insuperaveis por effeito desgraçado de uma usurpação destruidora». Por ello, había que adaptar la Iglesia Patriarcal a los medios del Estado, aunque se conservasen las preeminencias del Cardenal Patriarca. Y recordaba que la Basílica de Santa María la Mayor había sido erigida en tiempos del fundador de la Corona, Alfonso Enríquez, y elevada a Sede Arzobispal por Juan I, a los que ponía como ejemplo a seguir para restaurar su antiguo esplendor. Así pues, la Iglesia Patriarcal de Lisboa quedaba suprimida, y en su lugar se restablecía la Basílica de Santa María la Mayor como Sede Arzobispal Metropolitana de la Provincia de Estremadura, con el mismo número de dignidades, canónigos y ministros que tenía antes. El Cardenal Patriarca conservaría sus títulos, privilegios y preeminencias, y sus sucesores serían Arzobispos Metropolitanos de Lisboa. La Sede dispondría del usufructo de los bienes vinculados a la Mitra de Lisboa antes de la fundación de la Patriarcal, mientras que los donados después serían nacionalizados. Por otra parte, una parte de sus dignidades eran jubilados (principales y monseñores) mientras

9 Carta pastoral de Carlos da Cunha, 19 de agosto de 1823, en Aniceto 2017, 368. El Patriarca sostenía que se estaba cumpliendo la profecía de san Pablo en la que advertía de que en los últimos tiempos la fe sería objeto del ataque de apóstatas e incrédulos. Ello lo achacaba a la proliferación de "malos libros», y recordaba que él había preferido exiliarse a jurar un texto constitucional que recogía la libertad de imprenta.

10 Según el patriarca Silva: «He da mesma palavra Lei, que se deriva o titulo, e o predicado de Legitimo. Mas só a ignorancia, ou a pertinacia, e a má fé, poderá duvidar, de que o chamado nas actuaes circunstancias he o Augusto Principe, o Senhor D. Miguel. Porque se ninguem duvída, de que a Nação Brazileira, que antes era Portugueza, passou a ser estrangeira para nós depois da sua independencia, que razão se poderá descobrir, para que o seu Augusto Imperador deixasse de contrahir esta mesma qualidade de estrangeiro, tendo-se-lhe unido, e encorporado de sua livre vontade, e vivendo no meio della? $\mathrm{E}$ quem ignora, que nossas Leis fundamentaes excluem da successão do Throno os Principes estrangeiros, e que neste caso ella não póde competir, senão a seu Augusto Irmão, nosso legitimo, e natural Soberano, o Senhor D. Miguel?». Carta pastoral de 9 de junio de 1828, ibídem 419.

11 Véase Lousada 1989 y Silva 1993.

12 Sobre Patrício da Silva, Azevedo 2009. 
que los canónigos y otros empleados se incorporarían a la nueva Sede, a excepción de los que se hubiesen significado por el apoyo al príncipe Miguel. Finalmente, una comisión presidida por el Patriarca dilucidaría todos los asuntos relativos a la implantación del decreto: las congruas de las dignidades de la nueva Sede, aquellos eclesiásticos que «por sua sciencia, virtude, boa moral, e adhesão ao Governo Constitucional da Rainha» podrían incorporarse a la misma, los que serían jubilados y los que serían separados, así como qué bienes eran de la Patriarcal y cuáles de la Basílica de Santa María la Mayor. ${ }^{13}$

El decreto de la extinción de la Iglesia Patriarcal coincidió con la ruptura de las relaciones entre el Estado liberal portugués y la Santa Sede. Las medidas de reforma de la Iglesia llevadas a cabo por el Gobierno lusitano desagradaban profundamente a la corte de Roma, que, por otra parte, simpatizaba con la causa del príncipe Miguel. Así pues, el papa Gregorio XVI lamentaría la extinción de la Iglesia Patriarcal, junto con el resto de disposiciones de la política del Portugal liberal hacia la Iglesia, en el consistorio de 1 de agosto de 1834. ${ }^{14}$ Por su parte, el 10 de enero de 1835 llegaba al patriarca Silva una carta regia confirmando el decreto de extinción de la Patriarcal, y ordenando que el nuevo cabildo fuese instalado el día 22, coincidiendo con la fiesta de San Vicente, patrón de la diócesis. La carta no se olvidaba de disponer que los canónigos usarían las mismas vestiduras que en los demás cabildos catedralicios del reino, señal inequívoca del fin de los privilegios que desde el siglo XVIII habían singularizado al Patriarcado de Lisboa respecto al resto de la Iglesia lusitana. El silencio del patriarca Silva, que no alzó su voz frente a unas medidas que tanto le afectaban, da buena cuenta del rápido acomodo a la nueva situación del antiguo Patriarca miguelista, auxiliado en el desempeño de sus funciones por el clérigo liberal y masón Marcos Pinto Soares Vaz Preto. ${ }^{15}$ Pero lo cierto es que el asunto de la Iglesia Patriarcal no había acabado con su supresión por el Gobierno liberal, pues no tenía la sanción definitiva de Roma. Al fin y al cabo, había sido un Sumo Pontífice quien había instituido con una bula esa corporación eclesiástica, por lo que tenía que ser la Santa Sede quien estableciese su disolución a través del mismo procedimiento canónico.

La polémica volvería a estar servida tras la muerte de Silva y el nombramiento de un nuevo Patriarca. El afortunado fue Francisco de São Luís Saraiva, un benedictino ilustrado que había sido educado en los tiempos en que el Marqués de Pombal quería implantar la moderna filosofía en Portugal. Eclesiástico de vasta cultura, Saraiva había comenzado su actividad política en tiempos del Trienio Vintista, cuando colaboró con las autoridades liberales y desempeñó los cargos de coadjutor del Obispo de Coimbra,

\footnotetext{
13 Collecção dos decretos 1835, 126-129.

14 Sobre la ruptura de las relaciones entre Portugal y la Santa Sede, véase Dória 2001. La lamentación del Papa en Gregorio XVI 1834, II.

15 Sobre Silva y su silencio ante el final de la Iglesia Patriarcal, Matos 2016, 106 y Azevedo 2009, 77. Según el testimonio del Marquês de Fronteira (1929, 46-47), el Patriarca pudo verse desbordado por los cambios sobrevenidos y, por ello, optaría por la inacción: «O cardeal Patriarcha, Patricio, no fim da vida, achacado, eten soffrido mil desgostos durante a usurpação, soffreu-os ainma maiores durante o Governo legitimo, e, por isso, de nada se occupava, deixando correr tudo á revelia». En cuanto al padre Marcos como Vicario General del Patriarcado, véase Carromeu 2013, 244-245.
}

al que luego sucedió en la Mitra, rector de la Universidad de la misma ciudad y diputado en las Cortes. Tras el regreso del absolutismo estuvo recluido en el Monasterio de Batalha y renunció a su obispado, y en 1826 su figura volvió a ser restituida, ahora como presidente de las Cortes. Tras el golpe de Estado de Miguel I en 1828, fue desterrado al Monasterio de los Paulistas en Serra de Ossa, donde permaneció hasta la entrada de los liberales en Lisboa en junio de 1833. Entre 1834 y 1835 desempeñaría el cargo de ministro del Reino en el gobierno cartista del Marqués de Palmela, y en 1836 presidiría la Cámara de los Pares. Su elección para la sede lisbonense coronaba una larga carrera política en las filas del liberalismo. ${ }^{16}$

La carta regia de nombramiento de Saraiva no dejaba lugar a dudas sobre la nueva condición de la sede de Lisboa. En reconocimiento a las virtudes y los servicios realizados por el benedictino tanto a la Iglesia como al Estado, la reina María II lo nombraba Patriarca, no del Patriarcado de Lisboa, sino «da Santa Igreja Archiepiscopal Metropolitana da Provincia de Estremadura». Asimismo, se reservaba expedir en su debido momento los despachos para que la nominación "surta todos os effectos correspondentes». ${ }^{17}$ Pero un año después el Patriarca Saraiva seguía siendo electo. El problema era que el Papa tenía que hacer efectivo el nombramiento de Saraiva, y por entonces las relaciones entre Lisboa y Roma estaban lejos de haberse normalizado por completo, si bien desde el ascenso de António B. da Costa Cabral como ministro de Negocios Eclesiásticos y de Justicia en noviembre de 1839 se abrieron las puertas a un entendimiento que fue concretándose en los años siguientes.

Una primera cuestión con la que tenía que enfrentarse el Gobierno era cómo había que redactar las cartas de nominación y presentación del Patriarca para que Roma diese su visto bueno. El Gobierno quería saber si se tenían que expedir como antes, llamándole únicamente "Patriarca» y sin hacer ninguna mención al decreto de 4 de febrero de 1834, o utilizando el título de "Patriarca Arcebispo de Lisboa» alegando aquella disposición. Además, los Patriarcas siempre habían sido Cardenales Patriarcas, por lo que había que averiguar si existía la posibilidad de que Roma distinguiese a Saraiva con esta dignidad. Las instrucciones que recibió en marzo de 1841 el embajador portugués en Roma, Visconde de Carreira le insistían en que había que resolver el tema del Patriarca electo con la Santa Sede. ${ }^{18}$ No obstante, Saraiva auguraba que el resultado iba a ser el mismo sea cual fuere la redacción que se eligiese: "a invencivel opposição, e repugnancia da Curia Romana, e o consequente desar, e quasi humiliação do governo de S. Magestade». Según el Patriarca electo, el problema no era si se utilizaba un título, el otro o ambos juntos, pues, al fin y al cabo, en ningún caso se alteraba el orden de la jerarquía eclesiástica. La dificultad estribaba en que la Iglesia Patriarcal se había disuelto sin pedir ni esperar la colaboración con Roma y, por tanto, al margen de todo proceso canónico. Y en un país que se decía católico, en el que la religión era un asunto de Estado, había

16 Al contrario que para sus predecesores, existen varios estudios sobre Saraiva: Ramos 1972; Cardoso 1995 y Clemente 2009.

17 Copia de la carta regia del nombramiento de Saraiva, 5 de enero de 1840, ANTT, FCC, parte B, c. 25, m. 20

18 Instrucções dadas ao Visconde de Carreira, 1 de marzo de 1841, ANTT, FCC, parte B, c. 21, m. 15. 
que procurar la sintonía entre el poder temporal y el poder eclesiástico:

E não se pense que eu queira com isto limitar de modo algum, ou coarctar o Poder do Principe no que toca ao Governo temporal do Reino: mas sustento, que dentro dos proprios limites do temporal, nos Estados catholicos, em que a Religião catholica he não só huma Sociedade Mystica, mas tambem huma Instituição Politica emque os povos são obrigados a professala, em que os negocios religiosos são intimamente ligados com os politicos; sustento (torno a dizer) que nestes Estados he muitas vezes necessario, e outras muitas conveniente, que o Poder temporal obre de acordo com o ecclesiastico, não precisamente por falta de autoridade legitima, mas sim por bem da harmonia e concordia, que sempre com grande cuidado se deve conservar entre o Sacerdocio e o Imperio. ${ }^{19}$

Alterar el antiguo lenguaje de las cartas de nominación y presentación ofrecería un argumento más para el disgusto de Roma, pero no hacerlo tampoco serviría para disimular los cambios realizados ante los ojos de la Santa Sede, y además podía considerarse una cobardía. Lo que había que hacer, ante todo, era restablecer las relaciones con el Papa para propiciar un contexto de entendimiento. $Y$ respecto a la cuestión de si había que pedir la dignidad cardenalicia, con la que todos los Patriarcas habían sido agasajados, Saraiva opinaba que se podía prescindir de ella. ${ }^{20}$

Según la respuesta de Carreira a Rodrigo da Fonseca Magalhães, Ministro de Negocios Extranjeros, Roma confirmaría al Patriarca electo, pero no estaba seguro de si concedería la púrpura cardenalicia que la reina pretendía pedir para su prelado. ${ }^{21}$ Respecto a la redacción de la carta de presentación del Patriarca electo, el problema de fondo era mucho más complejo, pues había que volver a disolver la Iglesia Patriarcal e instaurar la nueva Sede de Lisboa con la colaboración del Papa:

Resulta que a dita Carta nem póde ser expedida nos termos das antigas, porque isso seria evidentemente um dolo, conservando-se as disposições do Decreto que abolio a Patriarchal, nem tão pouco segundo a composição da nova Igreja, feita pela Auctoridade secular sem o concurso da Santa Sé, e conseguintemnte contra as regeas estabelecidas pela Disciplina actual da Igreja Catholica. E' pois necessario primeiro que tudo que a Igreja Patriarchal de Lisboa seja reconstruida canonicamente pelo Papa segundo a nova forma e denominação que o Govêrno quer dar-Ihe; e para remover quanto antes esta difficuldade, tomarei sobre mim de impetrar a necessaria Bulla, se isso for possivel. ${ }^{22}$

Pero para pedir la bula era necesario un entendimiento entre Lisboa y Roma que no terminaba de producirse, habida cuenta de que la Curia romana desconfiaba profundamente de las intenciones del Gobierno liberal portugués. Las noticias que llegaban a la corte pontificia de lo que ocurría en Portugal, posiblemente mediatizadas por agentes miguelistas -o eso, al menos, se pensaba desde Lisboa-,

19 Saraiva a Sousa, Lisboa, 18 de enero de 1841, ANTT, FCC, parte B, m. 6 .

20 Ídem.

21 Carreira a Magalhães, Roma, 7 de mayo de 1841, ANTT, FCC, parte B, c. 21, m. 15 .

22 Carreira a Magalhães, Roma, 18 de mayo de 1841, ibídem. alimentaban la intranquilidad del Pontificado respecto a los derroteros que podía tomar la Revolución liberal. Y lo que estaba ocurriendo en España, con el liberalismo progresista en el poder durante la regencia de Espartero, parecía confirmar esos recelos. Por ello, advertía Carreira, «não só serão inuteis todas as diligenias para obter a Bulla de reconstrucção da Sé de Lisboa, mas todas outras que se façem para terminar qualquer dos negocios ecclesiasticos desse Reino que dependan do concurso e da autoridade do Papa». ${ }^{23}$

Por tanto, hubo que esperar a que llegase el entendimiento definitivo entre Portugal y la Santa Sede, y este no empezó a verificarse hasta enero de 1842, cuando Roma nombró al Francesco Capaccini internuncio en Lisboa. ${ }^{24} \mathrm{~A}$ su vez, Palmela era nombrado ministro plenipotenciario para negociar con él al mes siguiente. Aquel incluso contemplaba la renuncia del Patriarca electo, a lo que el propio Saraiva estaba dispuesto si así lo mandaba la Reina o el Papa. ${ }^{25}$ Finalmente, no hizo falta que el Patriarca renunciase, pero, posiblemente debido a su difícil situación, escribió el 4 de diciembre al Papa una carta en tono conciliador. En ella afirmaba que lo que le había animado a aceptar el cargo de Patriarca no era la ambición personal, sino "o verdadeiro e sincero zelo da religião, o amor da Patria, o preceito da Augusta Reinha Fidelissima, e as instancias e persuasões de muitos varões de excellente virtude e prudencia». Como Patriarca, estaba desempeñando un servicio a la Iglesia, y por eso confiaba en que la Santa Sede le confirmaría. Y terminaba advirtiéndole sobre las intrigas que al lado del solio pontificio se vertían contra el sistema liberal en Portugal:

Creia-me Vossa Santidade, Ihe rogo. Nunca neste Reino de Portugal, tão benemerito da religião Christaã, devotissimo em todo o tempo á Santa Sé Apostolica Romana, existio machinação alguma tendente á destruição, e ruina da religião; nunca propensão alguma para a impiedade; nunca projecto, ou intento de propagar doutrinas licenciosas, ou menos orthodoxas. Os delirios, os erros, os desvarios momentaneos, a propria maldade, e até os improbos intentos de alguns poucos homens (se algum houver, ou ha) nunca se devem imputar a toda a nação, num ainda ao systema do seu governo (seja qual for o juizo que delle se faça) sem se podem haver como indole, e caracter propio do Povo Portugêz. ${ }^{26}$

Un día después de que Saraiva escribiese al Papa, Palmela tenía en sus manos las bases de la negociación de la sede de Lisboa. La archidiócesis habría de tener la categoría de "Sé Arquiepiscopal Metropolitana», como capital de una provincia eclesiástica, gobernada por un arzobispo que conservaría el título de Patriarca con todas sus distinciones. Todo ello establecido de manera canónica, con el concurso de la Santa Sede. Por su parte, el Estado se encargaría de mantener la sede lisbonense en función de las posibilidades

23 Carreira a Magalhães, Roma, 8 de julio de 1841, ibídem.

24 Desde que entrase en la Secretaría de Estado como minutante, Capaccini había desarrollado una carrera diplomática al servicio de la Santa Sede que le llevaría a Países Bajos, Inglaterra, Austria, Prusia y Nápoles antes de llegar a Lisboa. En 1844, un año antes de su muerte, sería recompensado con la púrpura cardenalicia. Véase el opúsculo de Gazola 1845.

25 Saraiva a Sousa, Lisboa, 24 de octubre de 1842, ANTT, FCC, parte B, m. 6 .

26 Saraiva a Gregorio XVI, Lisboa, 4 de diciembre de 1842, ibídem. 
económicas. Además, había que asegurarse de que la nominación y presentación de sus dignidades pertenecerían a la Corona. Capaccini no desestimó la propuesta, pero alegó que no tenía autorización para tratar este tema, que habría de ser abordado en Roma. ${ }^{27}$

Así pues, de la negociación en Roma se encargaría João Pedro Migueis de Carvalho, ministro plenipotenciario en la Santa Sede. El 12 de diciembre el Visconde de Algés, ministro de Negocios Eclesiásticos, le enviaba la carta de nominación del Patriarca, y el día 19 las instrucciones sobre la línea a seguir. Tenía que asegurarse de que las bulas de confirmación del Patriarca de Lisboa fuesen expedidas como las anteriores, sin ninguna alteración que pudiese minar el patronato de la Corona sobre la Iglesia. También habría de ocuparse de la organización definitiva del cuerpo capitular de la Sede. Así que le ordenaba solicitar una bula que concediese al Patriarca amplios poderes para que, con el consentimiento de la Corona, "componha a Sé da Santa Igreja Patriarchal Metropolitana de Lisboa, de modo que satisfaça decentemente, como é sincero desejo da Mesma Augusta Senhora e de Seu Governo, ao esplendor do Culto na primeira Metropole do Reino». ${ }^{28}$

El 3 de abril fue confirmado canónicamente el Patriarca de Lisboa, junto con el arzobispo de Braga y el obispo de Leira. Tres meses después, el Papa le entregaba la púrpura cardenalicia, distinguiéndolo de la misma manera que a sus antecesores. Y, finalmente, el 9 de noviembre de 1843 se expidió en Roma la bula Quamvis Aequo, por la que se creaba la nueva Iglesia Patriarcal, que sobrevivía así a la Revolución liberal, aunque reconvertida en sede arzobispal. ${ }^{29}$

\section{2. ¿PATRIARCADO DE INDIAS O PATRIARCADO DE ESPAÑA?}

En 1524 Clemente VII concedió el título de Patriarca de Indias Occidentales a Antonio de Rojas, arzobispo de Granada, presidente del Consejo de Castilla y capellán real de Carlos V. Se trataba de una petición de la Monarquía castellana desde tiempos de la regencia de Fernando el Católico, pues, como su denominación expresaba, vinculaba la administración eclesiástica de los territorios americanos con la de la metrópoli. No obstante, cuando la Santa Sede accedió a su institución, dejó bien claro que el contenido del título era solamente honorífico y que en ningún caso el Patriarca podía pasar a América, evitando así la posibilidad de que se crease una Iglesia en América encabezada por el Patriarca al margen de Roma. El título pasaría en 1610 al Procapellán del Rey, jefe espiritual de la Real Capilla en ausencia del Capellán Mayor, que era el Arzobispo de Santiago. El 14 de junio de 1753 la Real Capilla fue erigida en parroquia territorial y el Patriarca y Pro-capellán quedó investido como su prelado, lo que le hacía depositario de la amplia jurisdicción palatina, que incluía el Palacio Real de Madrid, los Reales Sitios y multitud de establecimientos religiosos

\footnotetext{
27 Dória 2001, 167-168.

28 Algés a Carvalho, Lisboa, 19 de diciembre de 1842, ANTT, FCC, parte B, c. 20, m. 14.

29 Sobre estos documentos pontificios, Abranches 1895, 227-228. Respecto a la confirmación del Patriarca, así como de otros obispos nombrados por el Gobierno liberal tras su victoria sobre el miguelismo, «Para a historia secretissima da confirmação dos bispos eleitos pela Rainha», 22 de diciembre de 1843, ANTT, FCC, parte B., c. 22, m. 16.
}

del Patronato de la Corona. Además, en 1762 también se atribuyó al Patriarca la jurisdicción eclesiástica castrense, que se renovaba cada siete años. Por tanto, a comienzos del siglo XIX este título meramente honorífico extendía su jurisdicción sobre un amplio territorio y una notable multitud de personas. $^{30}$

Con la muerte de Fernando VII y el advenimiento de la Revolución liberal, la dignidad patriarcal se convertiría en objeto de controversia y en un elemento de tensión en las relaciones entre la Iglesia y el Estado. El primer conflicto surgido en torno a este título ocurrió con el decreto de jubilación del Antonio Allué y Sessé, Patriarca de Indias desde 1820. La medida, tomada en marzo de $1834,{ }^{31}$ podía deberse a que su lealtad estuviese de parte del pretendiente Carlos, como parecen apuntar las informaciones del nuncio Luigi Amat al Secretario de Estado romano, Tommaso Bernetti, ${ }^{32}$ así como el hecho de que fuese nombrado en su lugar un eclesiástico entusiasta de la Constitución de Cádiz, el diocesano de Sigüenza, Manuel Fraile. Aunque también circuló la idea de que había sido su oposición al matrimonio entre la reina regente y el guardia de corps Fernando Muñoz. En cierta manera, la jubilación del Patriarca era el comienzo de una depuración profunda en la Real Capilla de Palacio, entre cuyo personal se multiplicaban los carlistas, si bien se reservaba para el prelado un final más decente que para muchos de sus empleados. ${ }^{33}$

La noticia de la jubilación del Patriarca no gustó nada a las autoridades romanas. Amat no dejaba de subrayar que la medida había sido tomada desde el ministerio de Estado, y no desde el de Gracia y Justicia, lo que era una irregularidad. Además, si bien el cargo de Pro-Capellán podía ser de elección del monarca de turno, el título de Patriarca era una dignidad eclesiástica que confería el Papa en consistorio. $Y$ el nuncio saliente, Francesco Tiberi, que todavía se encontraba en Madrid, era de la misma opinión. ${ }^{34}$ Incluso se negó a recibir el juramento de Manuel Fraile para ejercer su nuevo nombramiento, advirtiéndole que no podía ser Patriarca de las Indias y Obispo de Sigüenza al mismo tiempo, salvo que el Papa se lo permitiese, y que para ejercer sus funciones necesitaba la delegación de Allué y Sessé, que a ojos de Roma seguía siendo el legítimo Patriarca. El mismo Allué y Sesé protestaría ante el Marqués de Valverde, Mayordomo Mayor de Palacio, pues consideraba que, aunque podía desprenderse de los cargos que dependían de la elección de la reina, no podía verse privado de sus jurisdicciones espirituales «sin aprobación de la Santa Sede de donde únicamente dimanan», si bien abría la posibilidad a delegarlas a su sucesor. ${ }^{35}$ En cambio, Francisco Martínez de la Rosa le recordaba:

30 Sobre el Patriarcado de Indias, véase Jiménez de Pablo 2015 y Comella 2004. Generalmente, en las fuentes españoles se utiliza más "Real Capilla» que "Capilla Real», por lo que aquí haremos uso de ese término.

31 Decreto de 17 de marzo de 1834, AGP, Personal, c. 38, exp. 1 (Exp. Personal de Antonio Allué y Sessé), doc. 56

32 Amat a Bernettí, Madrid, 27 de marzo de 1834, en Cárcel Ortí 1982, 81-82.

33 Sobre la depuración en la Real Capilla en 1834, Moral Roncal 2004 y $2005,197-208$.

34 Tiberi a Bernetti, Madrid, 1 de abril de 1834, en Cárcel Ortí 1976, 824-826.

35 Allué y Sessé a Valverde, Madrid, 26 de marzo de 1834, AGP, Personal, c. 16925, exp. 43 (Exp. Personal de Manuel Fraile). 
10 la libre y omnímoda facultad que compete a los Reyes Católicos para hacer el nombramiento de Vice Capellán mayor; 2 o que en virtud de este nombramiento reconoce Su Santidad «que puede ejercer en todo y por todo la jurisdicción que le está cometida, como si se la hubiese conferido a él mismo»; 3o que el dicho Brebe [sic] no exige más requisito que el hacer la profesión de la fe; 40 que inmediatamente después de cumplir con este requisito, puede la persona nombrada por S. M. ejercer el empleo y la jurisdicción que por él le compete. ${ }^{36}$

Así pues, el debate estribaba en dónde se encontraban los límites entre el Estado y la Iglesia. Mientras Luigi, Tiberi y Allué entendían que el Patriarcado de Indias era una dignidad eclesiástica que, en última instancia, confería el Papa, el Gobierno moderado presumía que únicamente bastaba la designación de la reina y la profesión de fe prescriptiva para que el afortunado comenzase a ejercer las jurisdicciones de su cargo. Ese primer conflicto que surgió en el momento de transición del Antiguo Régimen al sistema liberal se solucionó optando por la vía propuesta por Tiberi y el propio Patriarca saliente: la delegación de las jurisdicciones ordinaria y castrense. Sin embargo, Roma no reconocería otro titular del Patriarcado que Allué y Sessé hasta su muerte en 1842. El problema ponía de relieve la singularidad de un cargo que se sustraía al control del sistema liberal, algo a lo que los liberales no estaban dispuestos a renunciar. Por eso, no dejaron de plantear proyectos para acomodar esa institución heredera del Antiguo Régimen a la nueva realidad.

Al principio de la regencia de María Cristina, y en el contexto de un intento de apertura política a través de una vía que conciliase el absolutismo más templando con el liberalismo más moderado, el gabinete de Martínez de la Rosa creó una Real Junta Eclesiástica en abril de 1834 para iniciar, con el concurso de Roma, una reforma del clero en España. Su objetivo era, según el decreto de su creación, de 22 de abril de 1834, recuperar el "nativo inimitable esplendor» de la Iglesia española, así como, en palabras de la reina, «afianzar el trono de mi excelsa hija contra la resistencia abierta y los ocultos manejos de los desleales y perjuros» y el mantenimiento de la religión frente a "los capciosos sofismas de tantos sectarios abortados por el orgullo». ${ }^{37}$ Entre otros integrantes, en ella participarían los eclesiásticos que ostentarían la dignidad patriarcal hasta 1852: el propio Fraile, que era su vicepresidente; Pedro José Fonte, arzobispo de México y presidente de la Junta; Juan José Bonel y Orbe, obispo de Córdoba; y el antiguo obispo de Cartagena, Antonio Posada. Los trabajos de la Junta, desarrollados en medio de numerosas dificultades, culminaron en una Exposición dirigida a la reina regente el 25 de febrero de 1836, en la que, entre otros asuntos, se abordaba la cuestión del Patriarcado. ${ }^{38}$

En su discurso preliminar, la Junta señalaba que la corte de España carecía de una sede diocesana, lo que constituía

${ }^{36}$ Martínez de la Rosa a Valverde, Aranjuez, 4 de mayo de 1834, ibídem.

37 Gaceta de Madrid, 28 de abril de 1834

38 Sobre los trabajos de la Junta, Revuelta 2010, 216-225. Una valoración de sus integrantes, desde la óptica ultramontana: «No hay pues que admirarse que tales sugetos hayan sido preferidos a los célebres Inguanzus de Toledo, Cienfuegos de Sevilla, Vélez de Santiago, Echanobe de Tarragona y a tantos otros sabios y santos prelados que todavía encierra la España», en Areso 1846, 140. una anomalía, y lo pretendía solventar con la creación de un obispado en Madrid, que también ostentaría el título de Patriarca de Indias, que «no teniendo nada de común con España, y siendo un mero título de honor, daría por lo menos cierto realce y decoro al nuevo prelado». En consecuencia, la base 5. a del proyecto reservaba este título para el obispo que habría de regir la diócesis madrileña. Además, en el Reglamento que desarrollaba la circunscripción de las diócesis se establecía que el prelado madrileño ejercería asimismo la jurisdicción de la Real Capilla y la del Vicariato General castrense. ${ }^{39}$ Se trataba, por tanto, de una tímida reforma en la que las jurisdicciones seguirían unidas en la misma persona, aunque acomodándolas en el nuevo mapa diocesano que pretendía implantar el liberalismo, para ajustar la división administrativa eclesiástica a la política.

No obstante, para cuando la Real Junta Eclesiástica dio a luz el fruto de sus desvelos, la dinámica política del país depararía nuevos horizontes que acabarían desbordando el tibio reformismo anterior. Tras la llegada del liberalismo progresista al poder en el verano de 1836, y el empuje definitivo hacia una Monarquía constitucional, el asunto del clero sería una materia a examinar, ya no por una junta de eclesiásticos, sino por una Comisión de Negocios Eclesiásticos de las Cortes. El nuevo arreglo del clero se presentó a las Cortes en la sesión de 21 de mayo de 1837 como un proyecto que pretendía acomodar la Iglesia española a «la ilustración del siglo, el estado de los negocios públicos y, sobre todo, la situación de nuestra hacienda». En él nada se decía de la Real Capilla, suprimía el Vicariato General Castrense y, en cuanto al Patriarcado, lo hacía recaer en el arzobispo de Madrid, como primado de España y capellán mayor de los ejércitos nacionales. No obstante, pasaba de ser «Patriarca de Indias» a "Patriarca de España», según dictaba el artículo 20: «La iglesia primada de Madrid tendrá por prelado un M. R. arzobispo, con el carácter y atribuciones de patriarca de España y capellán mayor de los ejércitos nacionales». ${ }^{40}$

La reforma ahora iba mucho más allá del mero acoplamiento del Patriarcado a una nueva demarcación administrativa eclesiástica, pues imponía un cambio sustancial en su naturaleza, lo que desembocó en algún que otro equívoco. A este respecto, el arzobispo Cienfuegos de Sevilla mostró su indignación por lo que consideraba una intromisión del poder temporal en los asuntos exclusivos de la Iglesia, pues, aunque el Patriarcado era un título de honor, era el Papa quien lo concedía. Además, en cuanto a la jurisdicción castrense, sostenía que el Patriarcado era «como un obispado estendido por todo reino, pero sin territorio fijo, erigido con las bulas de los Papas», y solo estos tenían la facultad de permitir el ejercicio de su jurisdicción, que se renovaba cada siete años, «de lo cual nada se dice en el dictamen, no sé si porque lo suponen sus autores, o por otro motivo». ${ }^{41}$ Lo cierto es que el arzobispo de Sevilla no entendía la profundidad del cambio: la condición de capellán mayor de los ejércitos nacionales no implicaba ya ninguna jurisdicción delegada de Roma en el Patriarca.

Esta y otras cuestiones salieron a relucir en la discusión del dictamen en las Cortes Constituyentes de agosto de

39 Exposición dirigida a S. M. 1836, 58 y 89.

40 Dictamen sobre la reforma y arreglo del clero, leído a las Cortes en la sesión de 21 de mayo de 1837, BNE, Sig: U/11277.

41 Cienfuegos 1838, 64-65. 
1837, un debate que reflejó la dificultad de intervenir en un asunto en el que Roma tenía demasiado que decir. En principio, hablar de un «Patriarcado de España» suponía, primero, eliminar el Patriarcado de Indias, y luego instaurar el otro, lo que no estaba exento de obstáculos, habida cuenta de la tensa relación entre Madrid y Roma. "¿Qué significa la creación de un Patriarca? Sobre quince siglos ha pasado la Iglesia de España sin este título, hasta que se creó el Patriarca de las Indias. Perdimos la América, y ya ese Patriarca no nos hace falta. ¿Nos hace falta otro Patriarca? No, señores». Esta era la opinión del diputado y ministro de Fomento Martín de los Heros. Y para hacer valer su opinión traía a colación lo ocurrido en Portugal con la creación del Patriarcado de Lisboa:

Se propusieron los consejeros de aquel Reino formar una especia de Roma en Portugal; se creó una iglesia patriarcal, se crearon diáconos y subdiáconos, vestidos de colorados como los Cardenales; se crearon monseñores y otra porción de empleados de menor categoría; y recuerdo, señores, que una vez que estuve en aquella patriarcal, que apenas era mayor el ámbito de esa galería, vi salir una multitud de hombres vestidos de negro, de encarnado y de morado, y me chocó ver una cosa que estaba en completa disonancia con el objeto eclesiástico que se propusieron sus autores.

¿Y qué ha resultado ahora que han venido las reformas a Portugal? Que lo primero que han tenido que hacer ha sido echar abajo todo eso. ¿Y no vendrá a suceder lo mismo entre nosotros? Yo creo que sí, porque habrá dificultad para la instalación del patriarcado, y en último resultado para nada nos sirve. ${ }^{42}$

Por su parte, el canónigo de Valladolid y canonista Manuel Joaquín Tarancón, favorable al establecimiento de una sede arzobispal en Madrid, se oponía a que se arrebatase a la de Toledo los títulos de metropolitana y primada, además de que veía incompatibles el Primado de España con el Patriarcado. Y no dejaba de señalar lo que creía que era un error de redacción: el título era «Patriarca de Indias» y no "Patriarca de España». Terció otro canónigo, Antonio Martínez de Velasco, de parte de la comisión encargada del proyecto de ley, desmintiendo tal error, a lo que respondió Tarancón que el nuevo título era una variación imprudente que podía llevar a pensar «que había en este augusto Congreso diferentes miras que las justas que le animan». El canonista tampoco entendía cómo se iba a suprimir el Vicariato General castrense al mismo tiempo que el arzobispo de Madrid quedaba como capellán mayor de los ejércitos nacionales. A ambas apreciaciones respondía Martínez de Velasco subrayando el carácter nacionalizador del nuevo Patriarcado de España. En tanto que se había perdido el imperio americano, no tenía sentido que fuese «de Indias». Y respecto a la jurisdicción castrense, quedaba eliminada porque era una vía de intervención de la Santa Sede en una cuestión nacional tan importante como la del ejército:

La comisión ha creído que la Iglesia de España no debe reconocer otra autoridad que la de sus obispos. La Iglesia de España considera al obispo de Roma como sucesor de san Pedro; pero no permitirá más que este

42 Diario de Sesiones de las Cortes Constituyentes, n. 289, 23 de agosto de 1837 .
Obispo, que como tal sucesor de san Pedro, tiene una supremacía moral en la Iglesia católica, ejerza ninguna autoridad de jurisdicción, pues este es un abuso que ha puesto la Iglesia de España bajo el dominio de una corte extranjera. Así, pues, el Vicariato General castrense ha dejado de existir como los tribunales de Cruzada, de la Rota y otros que tenían su origen en la curia de Roma. ${ }^{43}$

Finalmente, la redacción del artículo planteaba tantas dudas y reticencias que tuvo que ser suprimida la referencia al Patriarcado para que fuese aprobado. En todo caso, ni Madrid tuvo por el momento sede episcopal, ni jamás adquirió el rango de primada, como tampoco se eliminó la institución del Vicariato General Castrense. En suma, el debate patentizaba las contradicciones de una institución propia del Antiguo Régimen que el Estado liberal no se atrevía a reformar por completo porque escapaba de su esfera de actuación.

\section{CONCLUSIÓN}

En ambos países ibéricos, lo sucedido con sus respectivos Patriarcados tras la Revolución liberal nos confronta con un conjunto de contradicciones que surgieron del paso de Monarquía a nación conservando la religión como elemento fundamental. En el Antiguo Régimen la Iglesia formaba parte de la Monarquía, y por ello esta institución respondía a las necesidades de unas Coronas cuyos territorios se extendían más allá de la Península Ibérica, asegurando su integridad política a través de una misma fe y una administración eclesiástica unitaria. Pero, con la Revolución liberal, el Patriarcado era una fuente de cuestiones y problemas que incitaban a su reforma, cuando no a su supresión. En primer lugar, su supervivencia quedaba en tela de juicio desde el mismo momento en el que el grueso de los territorios americanos accedía a su independencia, tanto en el caso de España como en el de Portugal. Además, la Iglesia se había identificado tanto con la Monarquía absoluta durante el Antiguo Régimen que no terminaba de transigir con un sistema político que afirmaba un conjunto de libertades, como reflejan las simpatías por los correspondientes candidatos legitimistas tanto en el Patriarcado de Indias como en el Patriarcado de Lisboa.

No obstante, si motivos había para acometer la abolición de estas instituciones por parte del liberalismo, tampoco faltaban argumentos para conservarlas, aunque fuesen reformadas. Así, en Portugal la extinción del Patriarcado constituyó más una reconversión que una efectiva extinción, con mediación de una bula pontificia incluida, aunque los liberales se hubiesen adelantado a decretar su abolición. Sin embargo, tanto interés mostraron aquellos en acabar con la institución como en mantener el título de Patriarca y sus prerrogativas, en especial la calidad cardenalicia que había distinguido a su titular desde el siglo XVIII. Por su parte, en España se intentó la acomodación del Patriarcado al nuevo contexto, hasta el punto de proyectar un cambio de nombre - «Patriarcado de España»-que refleja bien la intención nacionalizadora. Pero, al mismo tiempo, cualquier mutación debía venir acompañada de la aquiescencia

43 Diario de Sesiones de las Cortes Constituyentes, n.o 291, 25 de agosto de 1837, para esta y las citas anteriores. 
de Roma, algo difícil de conseguir, y así lo había advertido Martín de los Heros en sede parlamentaria. Incluso un cambio de titular podía generar un conflicto con la Santa Sede, como evidencia el desagrado de los representantes pontificios en Madrid tras la jubilación de Antonio Allué y Sessé, lo que refleja también la dificultad de encontrar un límite claro entre las esferas de actuación respecto a unas instituciones que se encontraban entre la Monarquía, el Estado y la Iglesia. Finalmente, y tras diversos avatares, el Patriarcado de Indias ha subsistido hasta la actualidad, aunque desde la Segunda República no existe la jurisdicción palatina, la castrense acabó desgajada como un arzobispado en 1951 y la dignidad de patriarca está vacante desde la muerte de su último titular en 1963, Leopoldo Eijo y Garay

En suma, a pesar de las contradicciones y las paradojas, en España y en Portugal el liberalismo no renunció a su proyecto de nación católica. $Y$ algunas instituciones eclesiásticas, por muy «monstruosas» que pudieran parecer a primera vista, siempre podían ser susceptibles de algún tipo de transformación para encajar en el nuevo orden de cosas y coadyuvar a la "armonía y concordia» -como expresaba el Patriarca Saraiva - que debía existir entre el Sacerdocio y el Imperio en los países católicos.

\section{BiBLIOGRAFÍA CITADA}

Abranches, Joaquim dos Santos. 1895. Summa do Bullario Portuguez. Coimbra: F. Franá Amado.

Alonso, Gregorio. 2014. La nación en capilla. Ciudadanía católica y cuestión religiosa en España (1793-1874). Granada: Comares.

Aniceto, Ricardo, coord. 2017. Cartas pastorais dos Patriarcas de Lisboa. Vol. 1. Lisboa: Nova Tera.

Areso, José. 1846. Grito de religión. Barcelona: Pablo Riera.

Azevedo, Carlos A. Moreira. 2009. «D. Frei Patrício da Siva, O.S.A. (1826-1840)». En Os Patriarcas de Lisboa, edición de Carlos A. Moreira Azevedo, Sandra Costa Saldanha y António Pedro Boto de Oliveira, 73-80. Lisboa: Alêtheia - Centro Cultural do Patriarcado de Lisboa.

Cárcel Ortí, Vicente, ed. 1976. Correspondencia diplomática del nuncio Tiberi (1827-1834). Pamplona: Universidad de Navarra.

Cárcel Ortí, Vicente, ed. 1982. Correspondencia diplomática del nuncio Amat (1833-1840). Pamplona: Universidad de Navarra.

Cardoso, António M. de Barros. 1995. Ler na Livraria de Frei Francisco de São Luís Saraiva. Ponte de Lima: Câmara Municipal de Ponte de Lima.

Carromeu, Francisco. 2013. Arcebispo e maçon: o padre Marcos na reforma liberal do Estado e da Igreja (1820-1851). Lisboa: Colibrí.

Cienfuegos, Francisco Javier. 1838. «Observaciones dirigidas al Soberano Congreso Nacional por el Cardenal Arzobispo de Sevilla, sobre el dictamen de proyecto de ley acerca de la reforma y arreglo del Clero». La voz de la religión tomo II: 46-86.

Clemente, Manuel. 2009. «D. Frei Francisco de São Luís Saraiva, O.S.B.» (1840-1845)». En Os Patriarcas de Lisboa, edición de Carlos A. Moreira Azevedo, Sandra Costa Saldanha y António Pedro Boto de Oliveira, 81-88. Lisboa: Alêtheia - Centro Cultural do Patriarcado de Lisboa.

Collecção das cartas de lei, decretos, etc. das Cortes Geraes, Extraordinarias e Constituintes da Nação Portugueza. 1822. Coimbra: Imprensa da Universidade.
Collecção dos decretos, resoluções e ordens das Córtes Geraes, Extraordinarias e Constituintes da Nação Postugueza. 1822. Parte I. Coimbra: Imprensa da Universidade.

Collecção dos decretos e regulamentos mandados publicar por Sua Magestade Imperial o regente do reino. 1835. Lisboa: Imprensa Nacional.

Comella, Beatriz. 2004. La jurisdicción eclesiástica palatina en los patronatos reales del Buen Suceso y de Santa Isabel de Madrid (1753-1831). Madrid: Fundación Universitaria Española.

Dória, Luís. 2001. Do cisma ao convénio: Estado e Igreja de 1831 a 1848. Lisboa: Imprensa de Ciências Sociais.

Exposición dirigida a S. M. el 25 de febrero de 1836 por la Real Junta Eclesiástica encargada de preparar el arreglo del clero; y trabajos hechos por la misma Junta con este objeto. 1836. Madrid: Miguel de Burgos.

Fernández de los Ríos, Ángel. 1868. El futuro Madrid. Madrid: Biblioteca Universal Económica.

Gazola, Carlo. 1845. Vita ed azioni del cardinale Francesco Capaccini. Roma: Tipografia delle Belle Arti.

Gregorio XVI. 1834. Allocutio habita in consistorio secreto Kalendis Augustianni MDCCCXXXIV. Roma: Reverendae Camarae Apostolicae.

Jiménez de Pablo, Esther. 2015. "La Capilla Real: Capellán Mayor, Limosnero Mayor y Patriarca de las Indias». En La corte de Felipe IV (1621-1665): Reconfiguración de la Monarquía Católica, edición de José Martínez Millán y José Eloy Hortal Muñoz, vol. I, 565-608. Madrid: Polifemo.

Lousada, Maria Alexandre. 1989. «O Miguelismo, um dicurso contrarevolucionário». En Do Antigo Regime al liberalismo, 1750-1850, 112-121. Lisboa: Vega.

Marquês de Fronteira. 1929. Memórias, edición de Ernesto de Campos de Andrada. Parte V-VI. Coimbra: Imprensa da Universidade.

Matos, Luís Salgado de. 2016. O Patriarcado de Portugal. Três séculos de uma instituição lisboeta, nacional e católica (1716-2016). Lisboa: Ars Longa.

Millán, Jesús y María Cruz Romeo. 2015. "La nación católica en el liberalismo. Las perspectivas sobre la unidad religiosa en la España liberal, 1808-1868». Historia y Política 34: 189-209.

Moral Roncal, Antonio M. 2004. «iLos carlistas en Palacio! La depuración política de la Capilla Real (1834-1835)». Espacio, Tiempo y Forma. Serie V, Historia Contemporánea 16: 91-104.

Moral Roncal, Antonio M. 2005. iEl enemigo en Palacio! Afrancesados, liberales y carlistas en la Real Casa y Patrimonio (1814-1843). Alcalá de Henares: Universidad de Alcalá.

Pinto, Sérgio Ribeiro. 2017. Servidores de Deus e funcionarios de César: o clero paroquial da Monarquia à República (1882-1917). Maia: Cosmorama.

Ponces, Teresa. 2009. «D. Carlos da Cunha (1818-1825)». En Os Patriarcas de Lisboa, edición de Carlos A. Moreira Azevedo, Sandra Costa Saldanha y António Pedro Boto de Oliveira, 67-72. Lisboa: Alêtheia - Centro Cultural do Patriarcado de Lisboa.

Portillo Valdés, José María. 2006. Crisis atlántica. Autonomía e independencia en la crisis de la Monarquía Hispana. Madrid: Marcial Pons - Fundación Carolina.

Portillo Valdés, José María. 2007. «De la Monarquía Católica a la nación de los católicos». Historia y Política 17: 17-35.

Portillo Valdés, José María. 2012. "La crisis imperial de la Monarquía Española». Historia y Espacio 39: 160-177.

Ramos, Luís A. de Oliveira. 1972. O Cardeal Saraiva. Oporto: Faculdade de Letras.

Revuelta, Manuel. 2010. La exclaustración (1833-1840). Madrid: CEU Ediciones.

Silva, Armando Malheiro da. 1993. Miguelismo: ideología e mito. Coimbra: Minerva. 